Situs Jurnal : $\underline{\text { http://ejurnal.stiepancasetia.ac.id/index.php/jieb }}$

Jilid 4 Nomor 1 Maret 2018

Hal 087 - 092

\title{
PENGARUH SERVANT LEADERSHIP DAN DISIPLIN KERJA TERHADAP KINERJA PEGAWAI PADA DINAS PEKERJAAN UMUM (PU) PENGAIRAN KABUPATEN KAPUAS KALIMANTAN TENGAH
}

\begin{abstract}
Muliadi*
Abstract: This study aimed to analyze the effect of servant leadership and work discipline on the employees performance of the Water Field of the Housing and Settlement, Spatial Planning, and Public Works Department, and Spatial Planning, Kapuas Regency, Central Kalimantan Province. This research is classified as causal research that measures the relationship between variables. The data collection methods were interviews and questionnaires. The method of data analysis was quantitative method. The results of this study were (1) servant leadership and work discipline has simultaneous influences on performance and (2) discipline has a positive and significant effect on the performance.
\end{abstract}

Keywords: servant leadership, work discipline, performance

Abstrak: Penelitian ini bertujuan untuk menganalisis pengaruh servant leadership dan disiplin kerja terhadap kinerja pegawai Dinas Pekerjaan Umum, Penataan Ruang, Perumahaan dan Kawasan Pemukiman Kabupaten Kapuas Provinsi Kalimantan Tengah pada Bidang Pengairan. Penelitian ini merupakan jenis penelitian kausal yang mengukur hubunganhubungan antar variabel penelitian. Metode pengumpulan data yang digunakan adalah wawancara dan kuesioner. Metode analisis data menggunakan metode kuantitatif yaitu dengan metode Analisis Regresi Linear Berganda. Hasil penelitian menunjukkan (1) servant leadership dan disiplin kerja secara bersamasama memiliki pengaruh terhadap kinerja; dan (2) displin kerja berpengaruh secara positif dan signifikan terhadap kinerja.

Kata kunci : servant leadership, disiplin kerja, kinerja

\section{Latar Belakang}

Dalam organisasi, sumber daya manusia (SDM) pada umumnya memiliki latar belakang sosial, budaya, ekonomi, dan motivasi yang berbeda sehingga perilakunya dapat berpengaruh terhadap kinerja organisasi. Oleh sebab itu, setiap unit kerja yang akan mengembangkan kemampuan SDMnya harus mengerti sifat dan kemampuan yang diperlukan untuk menyelenggarakan fungsifungsi yang berbeda dalam organisasi.

Suatu organisasi yang sedang berkembang diharapkan dapat meningkatkan kompensasi dan kepuasan pegawai karena tingkat kinerja. Pada gilirannya kepuasan pegawai akan memotivasi pegawai untuk kerja keras mendukung supaya organisasi untuk mencapai mencapai tujuan organisasi.

Oleh karena itu, pertanyaan yang ingin dijawab oleh penelitian ini adalah "Apakah Servant Leadership dan disiplin kerja berpengaruh signifikan terhadap kinerja pegawai pada Dinas Pekerjaan Umum (PU) Pengairan Kabupaten Kapuas Kalimantan Tengah?”. 


\section{Kajian Literatur}

Servant leadership atau kepemimpinan pelayan adalah konsepkepemimpinan etis yang diperkenalkan oleh Greenleaf pada tahun 1970. Menurut Spears (2010:255) pemimpin yang melayani adalah seorang pemimpin yang mengutamakan pelayanan, dimulai dengan perasaan alami seseorang yang ingin melayani dan untuk mendahulukan pelayanan, selanjutnya, secara sadar, pilihan ini membawa aspirasi dan dorongan dalam memimpin oranglain. Perbedaan ini nyata dari sikap yang dibawakan oleh si pelayan, pertama adalah merasa yakin bahwa kebutuhan tertinggi orang lain terpenuhi. Tujuanutama dari seorang pemimpin pelayan adalah melayani dan memenuhi kebutuhan pihak lain, yaitu secara optimal seharusnya menjadi motivasi utama kepemimpinan Stone, (2011:11). Pemimpin yang melayani pada akhirnya akan mengembangkan sikap indivudu disekitarnya dengan harapan memiliki sikap yang sama untuk melayani dengan baik. Model kepemimpinan pelayanan yang dikembangkan oleh Lantu (2007:48) memprioritaskan pengembangan karyawan sebagai hal yang utama dan pertama, secara tidak langsung pemimpin diharapkan mengarahkan perusahaan menuju keberhasilan jangka panjang dan berkelanjutan. Hal ini merupakan dampak dari perubahan perilaku yang melayani bawahan yang terjadi dalam fase yang berurutan dan berlangsung secara terus menerus.

Anoraga (2006;46) disiplin dalam KaMus Bahasa Indonesia susunan W.J.S. Poerwadarminta adalah: (1) latihan batin dan watak dengan maksud supaya segala perbuatannya selalu mentaati tata tertib, dan (2) ketaatan pada aturan dan tata tertib.

Menurut Smith dalam Anaroga (2001: 12), tujuan bekerja adalah untuk hidup, atau bekerja diperlukan karena adanya tujuan menopang kesejahteraan, yang tampaknya orang tidak bisa menikmati hidup. Oleh karenanya, kini kerja juga melibatkan masalah kebutuhan ekonomi, hanya kegiatan yang termotivasi oleh kebutuhan ekonomi saja yang dapat dikategorikan sebagai kerja, sedangkan orang yang tidak mendapatkan imbalan tidak dapat dikatakan bekerja.

Suatu organisasi yang baik selalu mempunyai aturan internal dalam rangka meningkatkan kinerja dan profesionalisme, budaya organisasi maupun kebersamaan, kehormatan, dan kredebilitas organisasi serta untuk menjamin tetap terpeliharanya tata tertib dalam pelaksanaaan tugas sesuai tujuan, peran, fungsi, wewenang dan tanggung jawab institusi tersebut.

Organisasi yang berjalan optimal tidak dapat dikaitkan sepenuhnya hanya pada kebutuhan ekonomi saja, karena pada kenyataannya faktor disiplin kerja mempunyai peranan yang tidak kalah penting untuk membentuk seseorang mempunyai tanggung jawab dalam bekerja.

Tujuan organisasi yang hendak dicapai peranan variabelvarabel tersebut saling mendukung dan berkaitan satu sama lainnya. Peranan individu dalam hal ini pegawai sangat penting karena suatu sistem, struktur, dan proses tidak akan berjalan dengan baik tanpa peranan individu dalam menjalankan variabelvariabel lainnya.

Salah satu peranan individu atau pegawai adalah dengan melaksanakan disiplin kerja yang berkaitan dengan kemampuan yang dimiliki pegawai tersebut. Kemampuan pegawai terbentuk dari pengetahuan dan keterampilan yang diperoleh baik dari lembaga pendidikan formal bersifat umum SD sampai perguruan tinggi) dan bersifat nonformal (kursus, seminar, dan lainlain). Dengan memiliki pengetahuan dan ketrampilan itu pegawai diharapkan mengetahui, memahami, melaksanakan dan mematuhi segala aturan dan normanorma dalam lingkungan kerja sebagai sistem organisasi pegawai negeri serta metodemetode tertentu dalam menyelesaikan sebuah pekerjaan atau tugastugasnya seharihari dengan baik yang akhirnya dapat memenuhi tujuan organisasi yang diharapkan.

Disiplin kerja merupakan suatu proses perkembangan konstruktif bagi pegawai yang berkepentingan karena disiplin kerja ditunjukan pada tindakan bukan orangnya. Disiplin juga sebagai proses latihan pada pegawai agar para pegawai dapat mengembangkan kontrol diri dan 
agar dapat menjadi lebih efektif dalam bekerja. Dengan demikian tindakan pendisiplinan juga hendaknya mempunyai sasaran yang positif, bersifatnya mendidik dan mengoreksi, bukan tindakan negatif yang menjatuhkan pegawai atau bawahan yang indisipliner dengan maksud tindakan pendisiplinan untuk memperbaiki efektifitas dalam tugas dan pergaulan seharihari di masa yang datang bukan menghukum kegiatan masa lalu.

Adapun pengertian disiplin kerja menurut Husein (2000:95) adalah pegawai patuh dan taat melaksanakan peraturan kerja yang berupa lisan maupun tulisan dari kelompok maupun organisasi. disiplin kerja dapat diartikan pelaksanaan manajemen untuk memperteguh pedomanpedoman organisasi. Pendapat lain menurut Siswanto (2001:291) disiplin kerja sebagai sikap menghormati, menghargai, dan taat pada peraturan yang berlaku baik tertulis maupun tidak tertulis serta sanggup menjalankannya, tidak mengelak dangan sanksisanksi apabila melanggar tugas dan wewenang yang diberikan kepadanya.

Kurangnya kesadaran dan kesediaan untuk bertindak atau berprilaku sesuai norma dan peraturan atau undangundang menyebabkan individu atau pegawai berbuat indisipliner. Lebih lanjut lagi menurut Hasibuan (2011:193), dalam suatu organisasi umumnya individuindividu yang berada di dalamnya sadar akan adanya norma atau aturan organisasi dan mereka pun sadar akan tuntutan kepatuhan tehadap norma atau aturan tersebut. Norma itu sendiri merupakan standar atau aturan main yang diikuti oleh banyak orang. Perilaku yang ditunjukan oleh masingmasing individu pegawai mencerminkan sampai seberapa jauh pegawai tersebut konsekuen dan konsisten mengikuti dan mematuhi atau melanggar norma dan aturan yang berlaku di organisasii pemerintahan.

Kinerja adalah segala hasil capaian dari segala bentuk tindakan dankebijakan dalam rangkaian usaha kerja pada jangka waktu tertentu guna mencapaisuatu tujuan. Sebuah jawaban untuk pertanyaan dalam definisi kinerja menurut Robbin dalam Nawawi (2006:62), yakni kinerja adalah jawaban atas pertanyaan"apa hasil yang dicapai seseorang sesudah mengerjakan sesuatu. Mangkunegara (2000:67) mengatakan bahwa kinerja pegawai adalah hasil kerja secara kualitas dan kuantitas yang dicapai oleh seseorang pegawai dalam melaksanakan tugasnya sesuai dengan tanggung jawab yang diberikan kepadanya. Perhatian terhadap kinerja merupakan suatu hal yang perlu bagi sebuahorganisasi ataupun perusahaan. Kinerja bukan hanya sekedar mencapai hasil tapisecara luas perlu memperhatikan aspekaspek lain, sebagaimana definisi kinerja, kinerja (performance) adalah hasil kerja yangdapat dicapai oleh seseorang atau sekelompok orang dalam suatu organisasi, sesuai dengan wewenang dan tanggung jawab masingmasing, dalam rangkaupaya mencapai tujuan organisasi bersangkutan secara legal, tidak melanggarhukum dan sesuai dengan moral maupun etika. Terkhusus bagi lembaga publik, definisi kinerja yang demikian menjadi perhatian agar dapat menjalankan fungsi dan peran sesuai aturan dan menjadi teladan bagi lainnya. Dengan demikian, tidak akan ada tindakantindakan penyimpangan ketika setiap individu (pegawai) tidak melanggar hukum dansesuai dengan moral maupun etika. Berdasarkan definisidefinisi yang ada, dapat disimpulkan bahwa kinerja pegawai merupakan hasil kerja yang dicapai pegawai dalam jangka waktu tertentu guna mencapai suatu tujuan.

Berdasarkan pada serangkaian literatur yang telah dikemukakan, maka dapat disusun hipotesis yang ingin diuji pada penelitian ini sebagai berikut:

Ho1: $\beta_{1}=\beta_{2}=0$ Tidak ada pengaruh yang positif dan signifikan dari servant leadership dan disiplin kerja terhadap kinerja Pegawai.

Ho1: $\beta_{1}=\beta_{2} \neq 0$ Ada pengaruh yang positif dan signifikan dari servant leadership dan disiplin kerja terhadap kinerja Pegawai. 
Ho2 : $\beta_{1}=0$ : Tidak ada pengaruh yang positif dan signifikan dari Servant Leadership terhadap kinerja pegawai

Ha2 : $\beta_{1}>0$ : ada pengaruh yang positif dan signifikan dari Servant Leadership terhadap kinerja pegawai.

Ho3 : $\beta_{1}=0$ : Tidak ada pengaruh yang positif dan signifikan dari disiplin kerja terhadap kinerja pegawai

Ha3 : $\beta_{1}>0$ : ada pengaruh yang positif dan signifikan dari Servant Leadership terhadap kinerja pegawai.

\section{Metode Penelitian}

Penelitian ini bertujuan untuk menjelaskan hubungan kausalitas antara variabel dependen dengan variabel independen. Atas tujuan tersebut rancangan penelitian ini menggunakan metode explanatory research. Adapun model analisis yang digunakan adalah regresi linier berganda

Jenis data dalam penelitian ini terdiri atas data kuantitatif dan data kualitatif. Data kuantitatif yaitu data yang berbentuk angka, atau data kualitatif yang diangkakan dalam bentuk skoring. Data kuantitatif yang digunakan dalam penelitian ini dalam bentuk scoring hasil jawaban responden. Data kualitatif yaitu data yang dinyatakan dalam bentuk kata, kalimat, dan gambar. Data kualitatif yang digunakan dalam penelitian ini berupa teoriteori komitmen pegawai, kepemimpinan, tesis, dll., yang relevan dengan penelitian ini.

Sumber data dalam penelitian ini terdiri atas data primer dan data sekunder. Data primer merupakan data yang diperoleh secara langsung dari dari obyek penelitian. Pada penelitian ini, data primer diperoleh melalui penyebaran kuesioner kepada pegawai Dinas Pekerjaan Umum (PU) Bidang Pengairan Kapuas yang terkait dengan servant leadership (X1), dan disiplin kerja (X2) kinerja pegawai (Y). Data sekunder adalah data yang diperoleh secara tidak langsung dari data yang telah diperoleh sebelumnya. Data sekunder disini berupa dokumen dan litelatur seperti buku dan jurnal penelitian.

Populasi dalam penelitian ini adalah pegawai pada Dinas Pekerjaan Umum (PU) Bidang Pengairan Kapuas sebanyak 80 orang. Teknik pengambilan sampel menggunakan metode sensus yaitu jumlah sampel merupakan seluruh populasi Arikunto (2011).

Alat analisis yang digunakan dalam penelitian ini adalah analis regresi berganda linier. Model analisis jalur diformulasikan sebagai berikut:

$\hat{\mathrm{Y}}=\mathrm{bo}+\mathrm{b}_{1} \mathrm{X}_{1}+\mathrm{b}_{2} \mathrm{X}_{2}$

Keterangan:

$\hat{\mathrm{Y}} \quad=$ kinerja

$\mathrm{b}_{0} \quad=$ konstanta

$\mathrm{b}_{1}, \mathrm{~b}_{2}=$ koefisien regresi

$\mathrm{X}_{1}=$ servant leadership

$\mathrm{X}_{2}=$ displin kerja

\section{Hasil Penelitian dan Pembahasan}

Penelitian dilaksanakan dengan cara mengolah data menjadi informasi yang bermanfaat melalui serangkaian pengujian dengan alat analisa statistik. Penelitian ini dilakukan untuk menguji hipotesi berikut: 
Ho1 $: \beta_{1}=\beta_{2}=0$ Tidak ada pengaruh yang positif dan signifikan dari servant leadership dan disiplin kerja terhadap kinerja Pegawai.

Ha1 : $\beta_{1}=\beta_{2} \neq 0$ Ada pengaruh yang positif dan signifikan dari servant leadership dan disiplin kerja terhadap kinerja Pegawai.

Dari hasil uji $\mathrm{F}$, nilai $\mathrm{R}$ square sebesar 0,999 hal ini berarti 99,9\% Artinya model penelitian mampu menjelaskan dari perubahan kinerja 99,9. Standard error of estimate adalah 0,9956

Dari uji Anova atau F test, didapat $\mathrm{F}$ hitung adalah 2,667E4 dengan tingkat signifikansi 0,000 . Karena probabilitas $(0,000)$ jauh lebih kecil dari 0,005 maka model regresi bisa dipakai dan secara simultan signifikan, karena nilai sig nya $<0,05$.

Koefisien korelasi parsial menunjukkan pengaruh mana yang paling dominan dari variabel bebas yaitu servant leadership dan disiplin kerja terhadap kinerja pegawai. Untuk pengujian ini dihipotesiskan sebagai berikut ini.

Ho2 : $\beta_{1}=0$ : Tidak ada pengaruh yang positif dan signifikan dari Servant Leadership terhadap kinerja pegawai

Ha2 : $\beta_{1}>0$ : ada pengaruh yang positif dan signifikan dari Servant Leadership terhadap kinerja pegawai.

dan

Ho3 : $\beta_{1}=0$ : Tidak ada pengaruh yang positif dan signifikan dari disiplin kerja terhadap kinerja pegawai

Ha3 : $\beta_{1}>0$ : ada pengaruh yang positif dan signifikan dari Servant Leadership terhadap kinerja pegawai.

Berdasarkan pada hasil penelitian ini, maka dapat dirumuskan persamaan regresi dalam penelitian ini adalah sebagai berikut ini.

$Y=0,913+005+0,688$

Penulis menyimpulkan bahwa (1) konstanta 0,913, (2) koefisien regresi X1 B sebesar 005, dan (3) oefisien regresi X2 B sebesar 0,688.

Uji t menguji signifikansi konstanta dan vairabel dependen terlihat pada nilai sig atau besaran nilai probabilitas, dari hasil pengujian terlihat nilai sig X1 sebesar 0,64 dan nilai sig X2 0,00. Maka dari hasil pengujian uji $\mathrm{t}$ dapat di katakan koefisien regresi X1 tidak berpengaruh signifikan karena nilai lebih besar dari 0,005, sedangkan nilai koefisien regresi X2 berpengaruh signifikan karena nilai lebih kecil dari 0,005

Dari hasil pengujian data dapat diketahui bahwa servant leadership tidak berpengaruh terhadap kinerja dengan nilai 0,064 dan disiplin kerja berpengaruh terhadap kinerja pegawai Dinas Pekerjaan Umum (PU) Kabupaten Kapuas Bidang Pengairan karena dari hasil uji t diketahui bahwa nilai signya lebih kecil dari 0,05 sebesar 0,000 .

Berdasarkan Hasil penelitian dan dilakukan uji F dengan aplikasi SPSS 16 di atas dibuktikan bahwa servant leadership dan disiplin kerja berpengaruh signifikan terhadap kinerja 
pegawai pada Dinas Pekerjaan Umum (PU) Kabupaten Kapuas Bidang Pengairan. Hal tersebut dapat diketahui pada nilai anova dengan 0,000 lebih kecil dari 0,005 dan nilai R Square dengan $99,9$.

Sejalan dengan pendapat yang dikemukakan oleh Hariandja (2012:96) yaitu disiplin kerja merupakan bagian yang penting dalam kehidupan kerja. Hal ini mudah dipahami sebab disiplin kerja bisa mempunyai dampak yang luas terhadap kehidupan organisasi.

\section{Kesimpulan}

Berdasarkan hasil analisis yang dilakukan dalam penelitian ini, berikut beberapa kesimpulan yang dapat diambil sebagai berikut ini.

1. Servant leadership tidak berpengaruh signifikan dan disiplin kerja berpengaruh signifikan secara parsial terhadap kinerja pegawai Dinas Pekerjaan Umum (PU) Kabupaten Kapuas

2. Servant leadership dan disiplin berpengaruh secara simultan terhadap kinerja pegawai pada Dinas Pekerjaan Umum (PU) Kapuas, penelitian mampu menjelaskan dari perubahan kinerja.

3. Berdasarkan hasil penelitian, penulis juga menemukan bahwa dapat disimpulkan bahwa disiplin kerja berpengaruh dominan terhadap kinerja pegawai pada Dinas Pekerjaan Umum (PU) Kabupaten Kapuas

\section{DAFTAR PUSTAKA}

Anoraga Pandji, 2006, Manajemen Sumber Daya Manusia, Edisi 4, BPFE, Yogyakarta.

Arikunto S., 2011, Prosedur Penelitian Suatu Pendekatan Praktik, Rineka Cipta, Jakarta.

Greenleaf Robert K., 1970, "Antecedents of Job Satisfaction: A Study of Telecom Sector", International CrossIndustry Journal, Perspectives of Innovations, Economics \& Business.

Hasibuan Malayu S.P., 2011, Fungsi Dan Tipe Kepemimpinan, Bumi Aksara, Jakarta.

Hariandja, Marihot T.E., 2007, Manajemen Sumber Daya Manusia (Pengadaan, Pengembangan, Pengkompensasian, dan Peningkatan Produktivitas Pegawai), Grasindo, Jakarta.

Husein Umar, 2010, Perilaku Organisasi, Macanan Jaya Cemerlang, Jakarta

Mangkunegara Anwar Prabu, 2000, Kepemimpinan Dalam Meningkatkan Kinerja, Remaja Rosdakarya, Bandung.

Nawawi Hadari, 2006, Analisis Kepemimpinan, UGM Press, Yogyakarta.

Lantu Donald, 2007, Organizational Citizenship Behaviour: It's Nature, Antecedents, and Consequences, Thousand Oaks, California.

Siswanto, 2001, Analisis kepemimpinan terhadap kinerja karyawan Hotel Bali Bagus, Tesis, STIE Pancasetia.

Spears L.C., 2010, "Character and Servant Leadership: Ten Characteristics of Effective, and Caring Leaders, The Journal of Virtues \& Leadership

Stone G.A., 2011, Organizational Behavior, Third Edition, The Mc.GrawHill Companies Inc, New York. 